\title{
Stat 1 functions as a cytoplasmic attenuator of Runx2 in the transcriptional program of osteoblast differentiation
}

\author{
Sunhwa Kim, ${ }^{1,5}$ Takako Koga, ${ }^{1,2,5}$ Miho Isobe, ${ }^{1,2}$ Britt E. Kern, ${ }^{3}$ Taeko Yokochi, ${ }^{1}$ Y. Eugene Chin, ${ }^{4}$ \\ Gerard Karsenty, ${ }^{3}$ Tadatsugu Taniguchi, ${ }^{1,6}$ and Hiroshi Takayanagi ${ }^{1,2}$ \\ ${ }^{1}$ Department of Immunology, Graduate School of Medicine and Faculty of Medicine, University of Tokyo, Tokyo 113-0033, \\ Japan; ${ }^{2}$ PRESTO, Japan Science and Technology Corporation (JST), Kawaguchi, Saitama 332-0012, Japan; ${ }^{3}$ Department of \\ Molecular and Human Genetics, Baylor College of Medicine, Houston, Texas 77030, USA; ${ }^{4}$ Department of Pathology and \\ Laboratory Medicine, Brown University School of Medicine, Providence, Rhode Island 02912, USA
}

Bone remodeling is central to maintaining the integrity of the skeletal system, wherein the developed bone is constantly renewed by the balanced action of osteoblastic bone formation and osteoclastic bone resorption. In the present study, we demonstrate a novel function of the Stat 1 transcription factor in the regulation of bone remodeling. In the bone of the Stat1-deficient mice, excessive osteoclastogenesis is observed, presumably caused by a loss of negative regulation of osteoclast differentiation by interferon (IFN)- $\beta$. However, the bone mass is unexpectedly increased in these mice. This increase is caused by excessive osteoblast differentiation, wherein Stat1 function is independent of IFN signaling. Actually, Stat1 interacts with Runx2 in its latent form in the cytoplasm, thereby inhibiting the nuclear localization of Runx2, an essential transcription factor for osteoblast differentiation. The new function of Stat1 does not require the Tyr 701 that is phosphorylated when Stat1 becomes a transcriptional activator. Our study provides a unique example in which a latent transcription factor attenuates the activity of another transcription factor in the cytoplasm, and reveals a new regulatory mechanism in bone remodeling.

[Keywords: Stat1; Runx2; osteoblast; bone remodeling]

Supplemental material is available at http://www.genesdev.org.

Received June 3, 2003; revised version accepted June 24, 2003.

The integrity of the vertebrate skeletal system is maintained by two distinct regulatory processes: the embryonic developmental and postnatal regulatory processes (Olsen et al. 2000; Karsenty and Wagner 2002). In the former process, the development of the skeletal system depends on the differentiation of chondrocytes, osteoblasts, and osteoclasts, all of which coordinate endochondral and membranous bone formation. On the other hand, in the latter process, referred to as bone remodeling, the bone matrix is constantly degraded by osteoclasts and deposited by osteoblasts (Manolagas 2000). The balanced action of these two cell types is critical for the normal homeostasis of the skeletal system in adults. Therefore, tipping this balance in favor of either cell type sometimes leads to pathological conditions. Excessive bone resorption is seen in autoimmune arthritis, periodontitis, postmenopausal osteoporosis, Paget's disease,

\footnotetext{
${ }^{5}$ These authors contributed equally to this work.

${ }^{6}$ Corresponding author.

E-MAIL tada@m.u-tokyo.ac.jp; FAX 81-3-5841-3450.

Article and publication are at http://www.genesdev.org/cgi/doi/10.1101/ gad.1119303.
}

and bone tumors, whereas excessive bone formation or defective bone resorption lead to osteosclerosis or osteopetrosis (Rodan and Martin 2000; Takayanagi et al. 2000a; Teitelbaum 2000). Thus, the investigation of the regulatory mechanism of differentiation of these two cell types is important in the understanding of the physiology and pathology of the skeletal system.

Previously, we have shown that both type I and type II interferon systems (i.e., IFN- $\alpha / \beta$ and IFN- $\gamma$ systems) are critical for the regulation of the skeletal system by suppressing osteoclastogenesis (Takayanagi et al. 2000b, 2002b). These two IFNs exert their inhibitory functions by distinct mechanisms, as briefly described below (Stark et al. 1998; Taniguchi et al. 2001; Takayanagi et al. 2002c). During osteoclast differentiation, induced by RANKL (receptor activator of NF-ㅌ ligand), the IFN- $\beta$ gene is induced in osteoclast precursor cells and IFN- $\beta$ inhibits the differentiation by interfering with the RANKL-induced expression of c-Fos, an essential transcription factor for osteoclastogenesis. This inhibition is dependent on the IFN-activated transcription factor, interferon stimulated gene factor 3 (ISGF3), which consists of activated Stat1, Stat2, and a member of the family of 
interferon regulatory factors (IRFs), IRF-9. On the other hand, IFN- $\gamma$ is critical in the T-cell-mediated regulation of osteoclastogenesis. RANKL expression is induced by activated $\mathrm{T}$ cells, but RANKL signaling is negatively regulated by IFN- $\gamma$, which is also induced by the activated T-cells, thereby balancing RANKL signaling (Kong et al. 1999; Takayanagi et al. 2000b). Stat1 (signal transducer and activator of transcription 1) is required for this IFN- $\gamma$ signal-mediated inhibition, in which the phosphorylated Stat 1 forms a homodimer, termed IFN- $\gamma$-activated factor (GAF). Despite the distinct mechanisms of regulating osteoclast differentiation by IFN- $\beta$ and IFN- $\gamma$, Statl is involved in both mechanisms, suggesting the integral role of Stat 1 in the regulation of bone metabolism.

In this regard, it is interesting that an activating mutation in FGFR3 results in human achondroplasia, one of the most common congenital diseases characterized by dwarfism, and that Statl is involved in this pathogenesis (Rousseau et al. 1994; Deng et al. 1996). The skeletal malformation in achondroplasia is caused by the suppression of chondrocyte proliferation by excessive FGF signaling, leading to impaired endochondral ossification. FGF induces the phosphorylation of Stat1, and the suppressive effect of FGF on chondrocyte proliferation is not observed in the skeletal tissue derived from mice lacking Stat1, suggesting that activation of Stat 1 is involved in the suppressive effect of FGF on chondrocyte proliferation in endochondral bone formation during embryogenesis (Su et al. 1997; Sahni et al. 1999, 2001). Notwithstanding, it is unknown at present if and how Stat 1 is involved in the control of transcriptional program(s) of the skeletal system at the postnatal stage.

The transcription factor Runx2, also called Cbfa1, is a runt family transcription factor, and it plays a central role in the determination of osteoblast differentiation (Ducy et al. 1997, 2000). Targeted disruption of Runx2 results in the complete lack of bone formation by osteoblasts, revealing that Runx 2 is essential for both endochondral and membranous bone formation (Komori et al. 1997). The haploinsufficiency of the Runx2 gene leads to cleidocranial dysplasia in humans, and Runx $2^{+/-}$mice show a similar phenotype characterized by abnormal membranous ossification, suggesting that the expression level of Runx2 is closely related to the promotion of membranous ossification (Otto et al. 1997). Among growth factors involved in osteoblast differentiation, bone morphogenetic protein (BMP) family proteins are most notable, because they have a strong ability to induce ectopic bone formation in vivo (Wang et al. 1990; Yamaguchi et al. 1991), and targeted disruption of Tob, an inhibitory protein of BMP signaling, results in the increased bone mass (Yoshida et al. 2000). Other factors regulating bone formation include Fos family proteins, which function in the context of AP-1. Their stimulatory effect on bone formation is underscored by the phenotype of the transgenic mice of Fra- 1 and $\triangle F O S B$, similarly exhibiting enhanced bone formation (Jochum et al. 2000; Sabatakos et al. 2000).

In the present study, we first show an unexpected phe- notype in the skeletal system of the mice deficient in the Stat1 gene (Stat ${ }^{-/-}$mice). The bone of the mutant mice exhibits excessive osteoclastogenesis, which is expected from our previous report demonstrating the critical role of the IFN-activated ISGF3 in negative regulation of osteoclastogenesis. Surprisingly, however, the bone mass is increased in these mice, suggesting a possibility that Stat1 plays a critical role(s) in inhibiting the bone-forming process and that this inhibitory function dominates over the inhibitory function of bone-resorbing process in the context of IFN signaling.

To date, the negative regulatory mechanism of bone formation has been poorly understood. We show here that Stat 1 is involved in attenuating the transcriptional activity of Runx2 in a unique manner, that is, by interaction with Runx2 in the cytoplasm. This new function of Stat 1 is independent of IFN signaling. We further show that the in vitro differentiation of osteoblasts derived from the Stat1 ${ }^{-/-}$mice is increased, which is accompanied by the up-regulation of the DNA-binding activity of Runx2. Our results thus reveal a novel physiological function of Stat1 in the regulation of osteoblast differentiation in the postnatal stage, and offer an interesting example of an otherwise latent transcription factor in the cytoplasm that has an active and physiologically critical role.

\section{Results}

Increased bone mass in the Stat $1^{-/-}$mice

To investigate the physiological function of Stat 1 in the skeletal system, we examined the bone phenotype of Stat $1^{-/-}$mice (Meraz et al. 1996) at the age of $12 \mathrm{wk}$. We reported previously that both Stat1 and IRF-9 are required for IFN- $\beta$-mediated inhibition of osteoclastogenesis, suggesting that Stat1 participates in this inhibition in the context of ISGF3 (Takayanagi et al. 2002b). Consistently, we observed an increased osteoclast number and enhanced osteoclastic bone resorption in the tibia of the Stat $1^{-/-}$mice (Fig. 1A). Tartrate-resistant acid phosphatase (TRAP) staining of the epiphyseal area of adult mice shows that the Stat $1^{-/-}$mice have significantly more osteoclasts in vivo than the wild-type (WT) littermates (Fig. 1B), an observation similar to the mice deficient in one of the IFN- $\alpha / \beta$ receptor components, IFNAR1 (IFNAR1-/- mice; Takayanagi et al. 2002b).

Interestingly, however, longitudinal sections and soft $\mathrm{X}$-ray analysis of tibial bones of these mice suggested that the Stat1 ${ }^{-/-}$mice have an increased bone mass (Fig. $1 \mathrm{C}, \mathrm{D})$. There was no abnormality in the microscopic analysis of the epiphyseal plate (Fig. 1E). Microcomputed tomography $(\mu \mathrm{CT})$ analysis of the diaphysis of the long bone clearly shows that the cortex bone is markedly thickened (Fig. 1C). The ratio of cortex width to the bone diameter at the middle of tibia is greatly increased in the Stat $1^{-/-}$mice (Fig. 2A). Furthermore, bone morphometric analysis showed that the increase in bone volume was observed in the trabecular bone as well as in the cortex bone (Fig. 2B), and the bone mineral density 


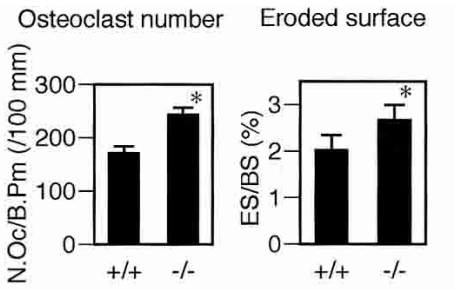

B

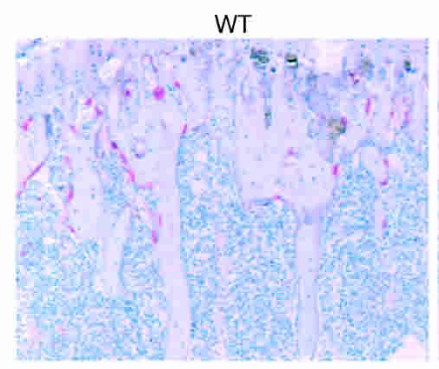

C

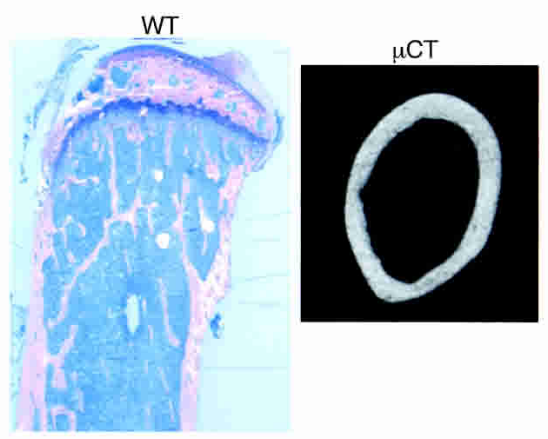

D
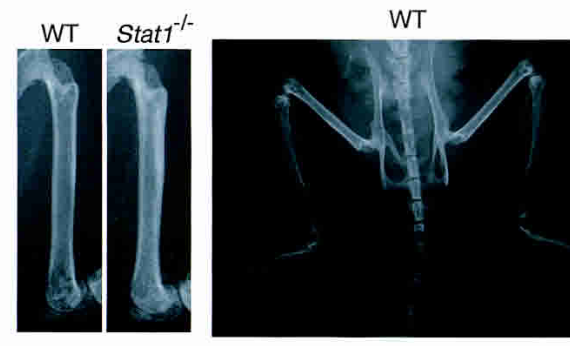

WT
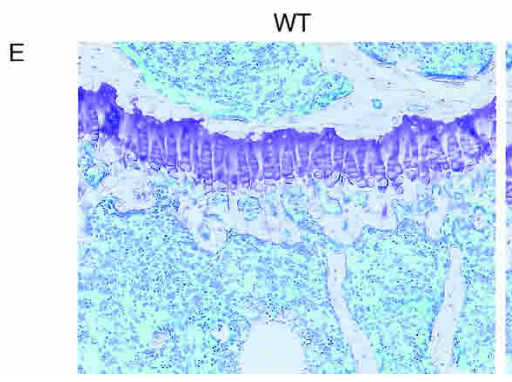
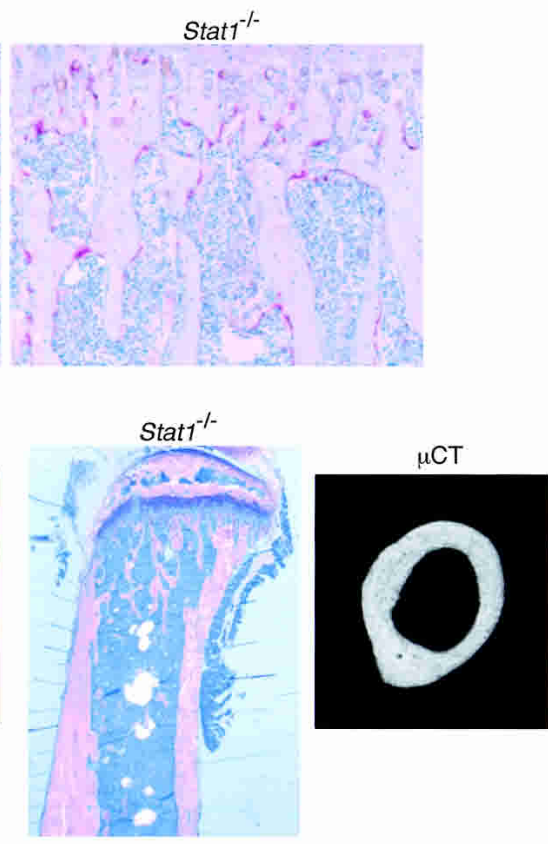

Stat1 $^{-1-}$

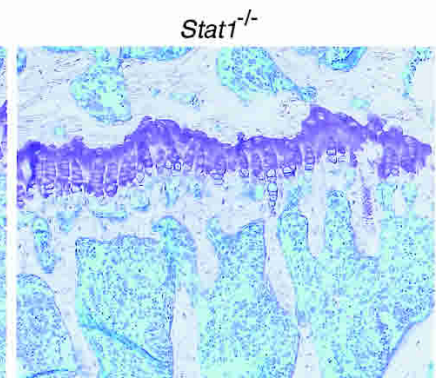

Stat $1^{-1-}$
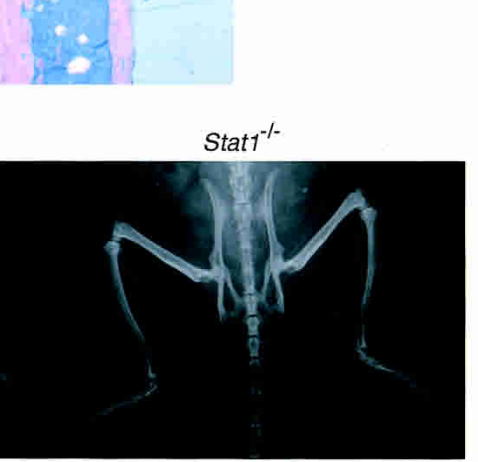

Osteoclast surface

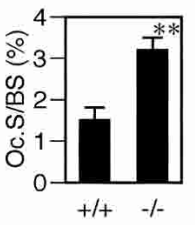

(BMD) of the femur was also up-regulated (Fig. 2C). We also examined the bone phenotype of mice lacking IRF-9 (IRF-9 ${ }^{-/}$mice), another essential molecule for ISGF3. In

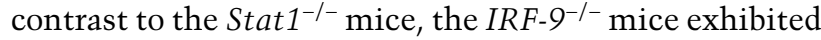
osteopenia, similar to the IFNAR1 $1^{-/-}$mice, along with lower bone mineral density compared with the wild-type mice (Fig. 2D-F). These observations are consistent with our previous report, indicating the essential role of IRF-9 in the RANKL-dependent autoinhibition of osteoclast differentiation via induction of IFN- $\beta$ (Takayanagi et al. 2002b). Unlike the Stat1 ${ }^{-/-}$mice, there was no abnormality in osteoblast parameters in the bone morphometric analysis of the $I R F_{-} 9^{-/-}$mice (see Supplementary Fig. S1). Taken together, these results suggest that Stat1 
Kim et al.

Figure 2. Enhanced bone formation and accelerated osteoblast differentiation in Stat $1^{-/-}$mice. $(A)$ Marked thickening of the cortex bone in Stat1 ${ }^{-/}$ mice. Cortex/diameter denotes the ratio of the sum of the cortex width to the bone diameter at the middle of the tibia. $(B)$ Cortex and trabecular bone volume was increased in Stat1 $1^{-/-}$mice at the age of 12 wk and $24 \mathrm{wk}$. (BV/TV) Bone volume per tissue volume. $(C)$ Bone mineral density (BMD) of 24-week-old Stat1 ${ }^{-/-}$mice measured in 20 longitudinal divisions of femur. BMD was up-regulated in Stat $1^{-/-}$mice from the proximal through the distal division ( $p<0.05, \# 1-\# 18)$. (D) Bone phenotype of IRF-9 $9^{-/-}$mice. $\mathrm{\mu CT}$ analysis in the middle of tibial diaphysis. (E) BMD is decreased in IRF-9-/- mice $(p<0.05$, \#3-\#18). See panel $C$ for details. $(F)$ Cortex width and bone morphometric analysis of IRF$9^{-/-}$mice. Cortex width is not significantly altered in IRF-9 $9^{-/-}$mice. Trabecular bone volumes decreased by $40 \%$. (BFR/BS) Bone formation rate per bone surface. $(G)$ Mechanical strength of the femur determined by the three-point bending test. Maximum load to failure and the energy resorption were greater in the femur of Stat $1^{-1-}$ mice than in those of wild-type mice, but the stiffness was not changed (data not shown).

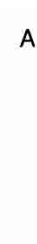

A
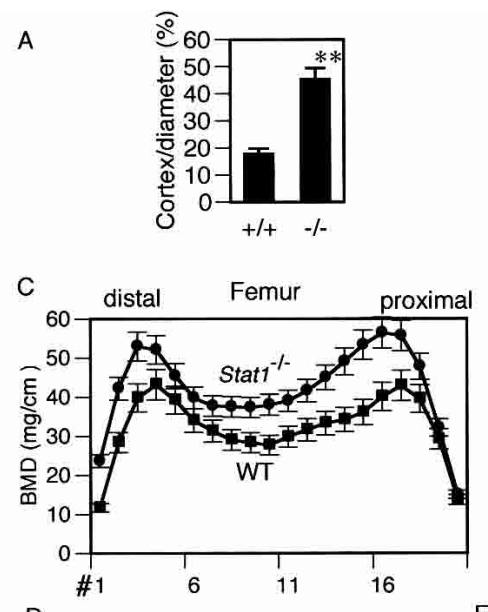

D

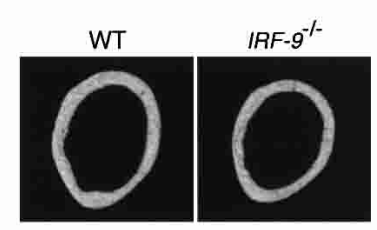

E

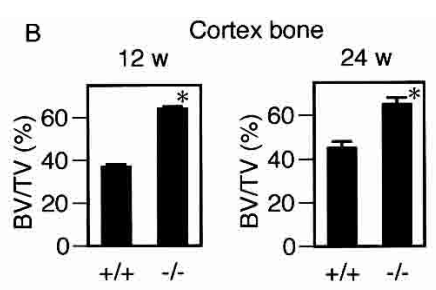

Trabecular bone
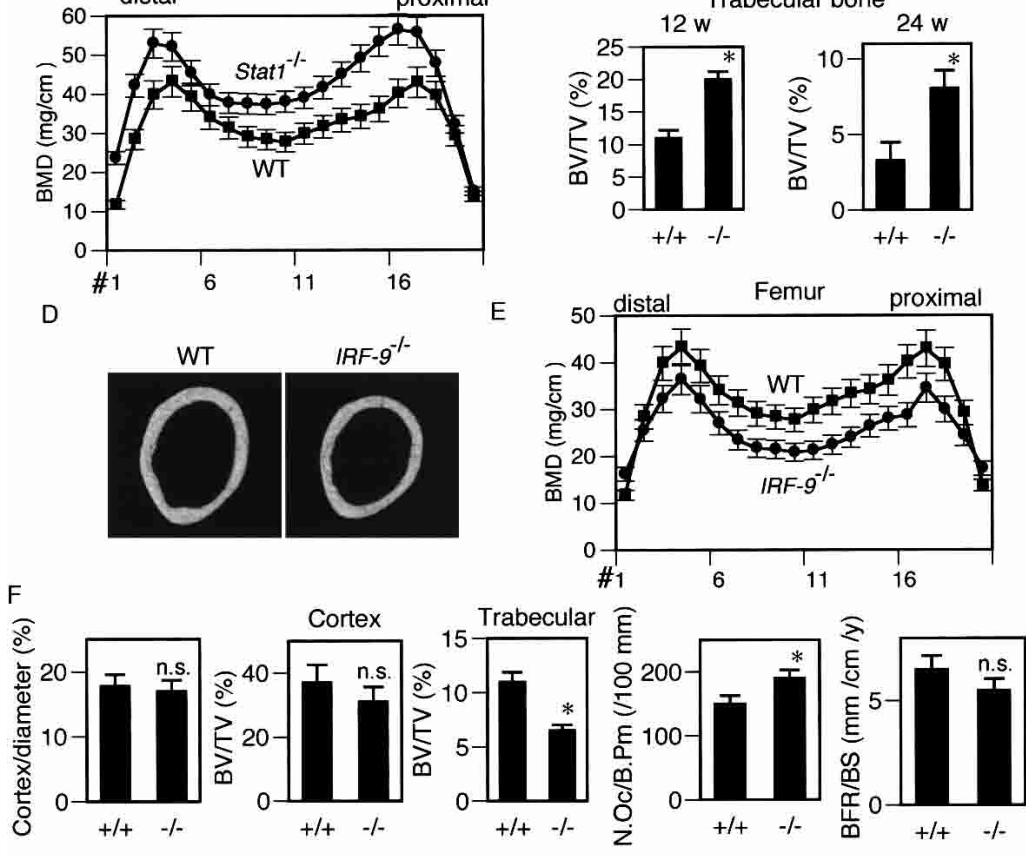

G
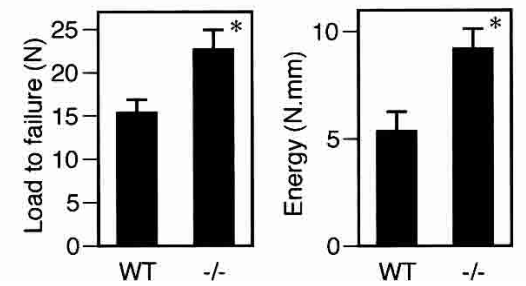

above results indicate that Stat1 is dispensable for the physiological regulation of chondrocyte proliferation and differentiation. Consistent with this theory, we detected little, if any, expression of Stat 1 mRNA in the normal skeletal tissue of developing embryos [embryonic days 12.5-16.5 (E12.5-E16.5); P.E. Bialek and G. Karsenty, unpubl.]. Furthermore, there was no difference in osteocalcin expression at E16.5 between wild-type and Stat1 ${ }^{-1-}$ mice (see Supplementary Fig. S2) and no acceleration of ossification in the newborn Stat $1^{-/-}$mice (see Supplementary Fig. S3), suggesting that the regulatory function of Statl is physiologically critical for the bone remodeling at the postnatal stage. It is notable that there was no severe abnormality in the gross development of skeletons, long bone length, or growth plate anatomy in Stat $1^{-/-}$mice (Fig. 1C-E), suggesting that the Stat1 ${ }^{-/-}$mice have no defect in the process of endochondral bone formation. Although Stat1 regulates chondrocyte proliferation in pathological conditions such as achondroplasia (Sahni et al. 1999), the

\section{Acceleration of osteoblast differentiation in the absence of Stat 1}

The unexpected bone phenotype of the Stat1 $1^{-/}$mice prompted us to examine the status of bone-forming osteoblasts in these mice. As shown in Figure 3A, bone 
A

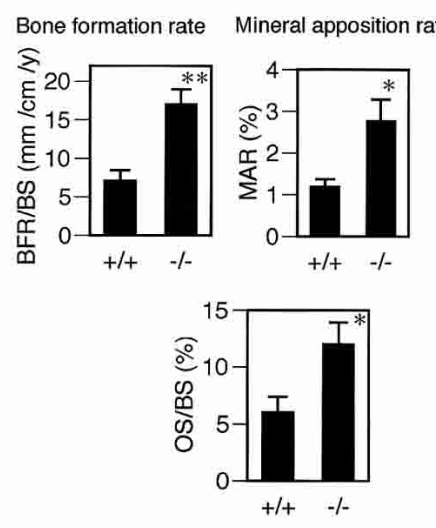

B
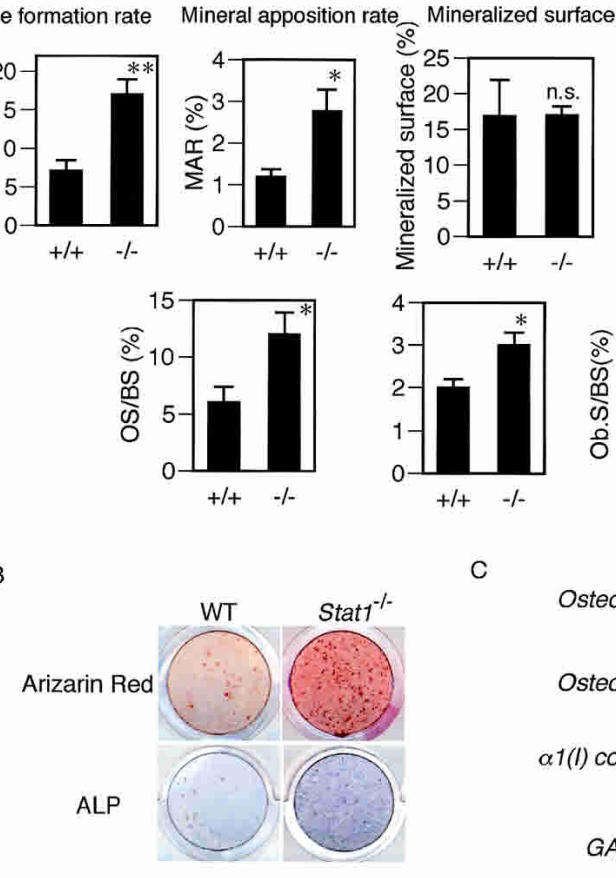
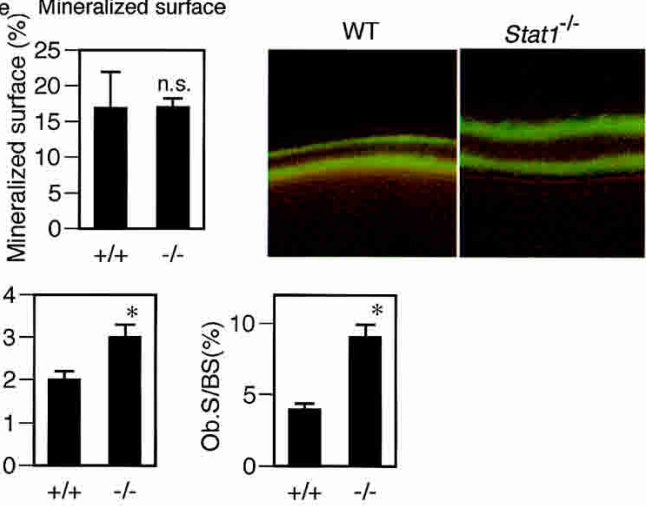

C

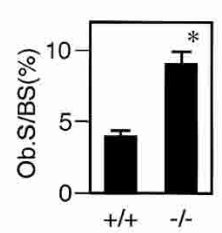

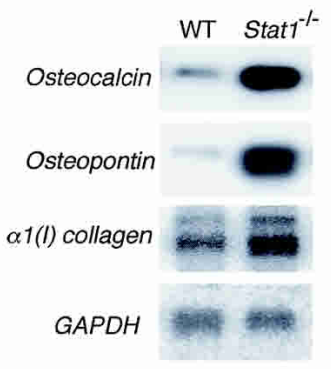
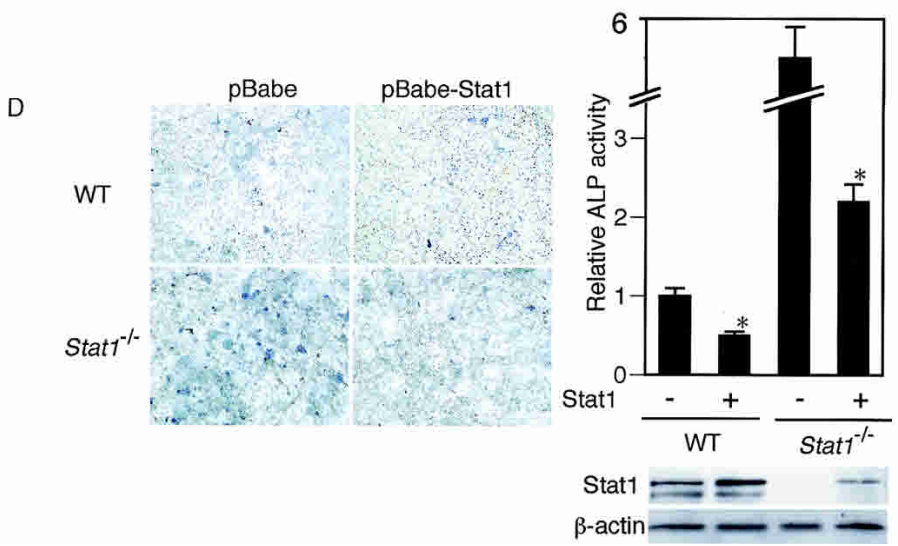

Figure 3. Increased bone formation and osteoblast differentiation in Stat1 $1^{-/}$mice. $(A$, left $)$ Bone morphometric analysis performed after bone labeling with calcein injections $(16 \mathrm{mg} / \mathrm{kg})$ with a 7 -d interval. $\mathrm{BFR} / \mathrm{BS}$ is elevated because of an up-regulated mineral apposition rate (MAR). (Right) Calcein labeling indicates the increased bone formation in the cortex bone of Stat1/-1- mice. (OS/BS) Osteoid surface per bone surface; (O.Th) osteoid thickness; (Ob.S/BS) osteoblast surface per bone surface. (B) Enhanced osteoblast differentiation derived from Stat1 ${ }^{-/}$mice shown by alizarin red and ALP staining. $(C)$ mRNA expressions of osteoblast differentiation marker genes such as osteocalcin, osteopontin, and type I collagen are up-regulated in Stat1 ${ }^{-/-}$osteoblasts (RNA blotting analysis). (D) Effect of retroviral expression of Stat1 gene in wild-type and Stat1 ${ }^{-/-}$osteoblasts. Osteoblast differentiation assayed by ALP activity was suppressed by expression of Stat1 in both wild-type and Stat $1^{-1-}$ cells $\left({ }^{\star} p<0.05\right.$ vs. Stat $\left.1^{-}\right)$. The expression level of Stat1 is analyzed by immunoblotting (lower right). morphometric analysis after calcein injection revealed a notable increase in bone formation rate (BFR). Osteoblast parameters such as osteoid surface/thickness and osteoblast surface were also up-regulated in the mutant mice, suggesting excessive osteoblast differentiation and matrix synthesis, compared with the wild-type mice (Fig. 3A).

We next studied the in vitro osteoblast differentiation of precursor cells obtained from the calvarial bone of the wild-type and Stat $1^{-/-}$mice. As shown in Figure 3B, osteoblast differentiation was significantly enhanced in the absence of Stat1, as revealed by notable increases in both alkaline phosphate (ALP) activity and bone nodule formation as determined by alizarin red staining. Furthermore, mRNAs for osteoblast differentiation marker genes such as osteocalcin, osteopontin, and type I collagen were all up-regulated in cultured osteoblasts from the Stat1 ${ }^{-/-}$mice (Fig. 3C).

We also examined the rates of cell proliferation and apoptosis in wild-type and Stat $1^{-/-}$osteoblasts; however, essentially no difference in cellular responses was observed between wild-type and Stat $1^{-/-}$osteoblasts, supporting the theory that the loss of Stat 1 selectively affects the osteoblast differentiation program (see Supplementary Fig. S4). To further address this issue, we ectopically expressed Stat 1 by retroviral gene transfer in wild-type and Stat1 ${ }^{-/-}$precursor cells, and examined their differentiation. As shown in Figure 3D, the expression of Stat1 suppressed osteoblast differentiation, without affecting the cell numbers of wild-type and Stat ${ }^{-/-}$ precursor cells. Collectively, these results suggest that Stat1 interferes with the osteoblast differentiation program and that the increased bone volume in the Stat ${ }^{-/-}$ mice is, indeed, caused by excessive bone formation by osteoblasts.

In view of the well-known fact that Stat 1 is activated in response to IFNs and other cytokines, such as leukemia inhibitory factor (LIF), interleukin (IL)-6, and on- 
costatin M (Meraz et al. 1996; Bellido et al. 1997), we examined if these cytokines inhibit the differentiation of osteoblasts in vitro, but no such evidence was obtained (data not shown).

\section{Enhanced response of osteoblasts to BMP-2 in the absence of Stat 1}

To gain insights into the mechanism by which Stat 1 interferes with the osteoblast differentiation program, we screened the mRNA expression of BMP family genes in wild-type and Stat1 ${ }^{-/-}$mice. However, there was no difference in the expression level of mRNA for BMP-2, BMP-4, BMP-6, and BMP-7, which are known to be potent stimulators of osteoblast differentiation (Fig. 4A). Although BMP-3 expression is up-regulated in Stat ${ }^{-1-}$ cells, BMP-3 is shown to negatively affect the bone mass (Daluiski et al. 2001). These results make it unlikely that Statl exerts its inhibitory effect on osteoblast differentiation by affecting the expression of BMPs that promote their differentiation.

We next examined the differentiation of wild-type and Stat $1^{-/}$osteoblasts in the presence of exogenous BMP-2, one of the best-known BMPs that stimulate osteoblast differentiation. Interestingly, enhanced osteoblast differentiation was observed in precursor cells from the Stat $1^{-/-}$mice relative to those from the wild-type mice when stimulated with exogenous BMP-2 (Fig. 4B,C), suggesting that Stat1 is involved in the negative regulation of the signaling pathway and/or transcriptional mechanism operating downstream of BMP-2.

\section{Enhanced activation of Runx2 in Stat $1^{-/-}$osteoblasts}

The above results provided us a cue to further analyze the molecular basis of excessive osteoblast differentia- tion in the absence of Stat 1 , that is, the role of Stat 1 in BMP-2 signaling events. Briefly, BMP-2 binds to its receptor, which induces the phosphorylation of Smad family proteins such as Smad1, Smad5, and Smad8, resulting in the formation of a trimetric complex with Smad4 (Heldin et al. 1997; Massague 2000). The Smad complex translocates to the nucleus and cooperates with another class of transcription factor, Runx2, to activate the transcription of osteoblast-specific genes (Zhang et al. 2000; Ito and Miyazono 2003). Moreover, Runx2 expression is induced by BMP-2 (Lee et al. 2000). Then, we examined the effect of Stat 1 on the activities of Runx 2 and Smad using two luciferase reporter genes linked to a Runx2dependent osteocalcin promoter (1050 OC-luc) or an artificial promoter that responds to Smads (12XGCCGluc).

As shown in Figure 5A, the coexpression of Stat 1 resulted in a strong inhibition of the Runx2-dependent activation of the osteocalcin promoter, without affecting the Smad1-dependent promoter activation, suggesting that Stat1 selectively interferes with the transcriptional activity of Runx2. In this regard, it is worth noting that no discernible Stat1-binding sites are present in the osteocalcin promoter (Javed et al. 1999), indicating that Stat 1 interferes with Runx 2 activity without binding to the promoter. In fact, an electrophoretic mobility shift assay (EMSA) using the Runx2-binding probe, revealed that the DNA-binding activity of Runx2 is up-regulated (by approximately fivefold) in Stat $1^{-/-}$osteoblasts, although the Runx2 protein level remained the same as that in wild-type osteoblasts (Fig. 5B, upper panel). BMP-2 stimulation caused an increase in Runx2 protein level in both wild-type and Stat $1^{-/-}$osteoblasts, and the DNA-binding activity of Runx 2 was also markedly increased (by approximately fourfold) in Stat1 ${ }^{-/}$osteo-
Figure 4. Effect of Stat1 deficiency on the expression of the BMP family and the response to BMP-2. (A) mRNA expression of BMP family genes in wild-type and Stat1 ${ }^{-1-}$ osteoblasts in the presence or absence of BMP-2 (RNase protection assay). There was no difference in the expression of osteogenic members such as BMP-2, BMP-4, and BMP-7. (B) The differentiation of wild-type and Stat $1^{-/-}$osteoblasts in the presence of exogenous BMP-2. Stat1 ${ }^{-/-}$osteoblasts show enhanced ALP activity and mRNA expression of the ALP gene even in the presence of excessive BMP-2. $(C)$ Bone nodule formation is more significant in Stat $1^{-/}$osteoblasts than in wild-type osteoblasts even with stimulation of BMP-2 (alizarin red staining).
A

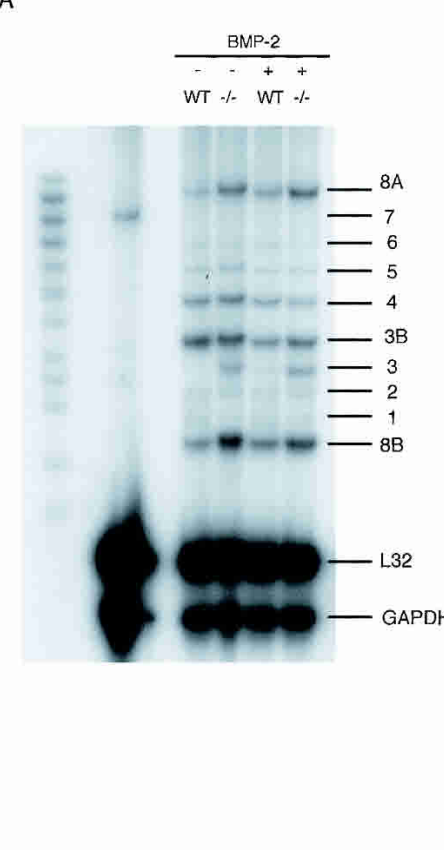

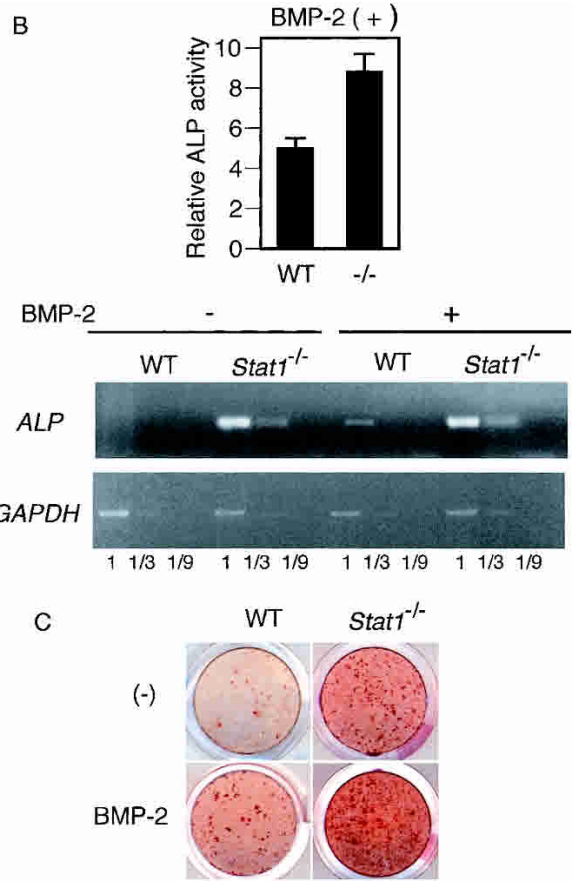



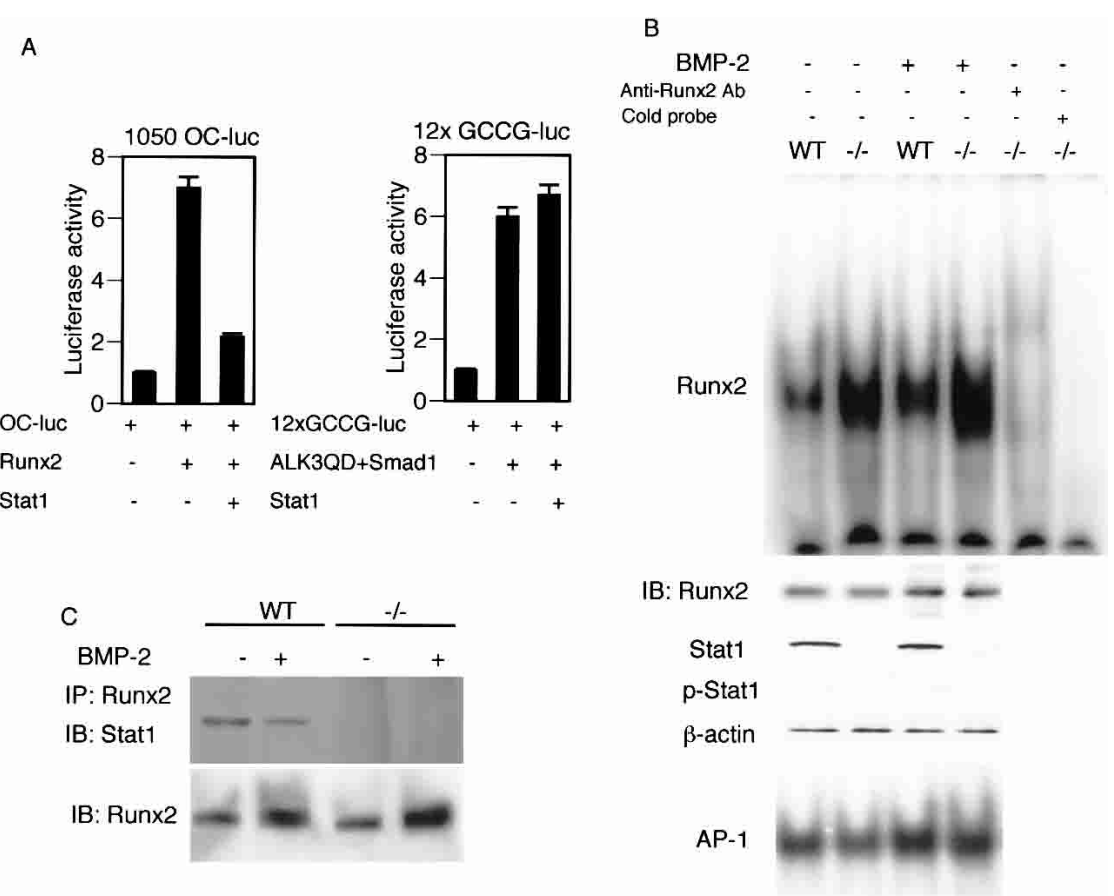

Figure 5. Runx2 transcriptional activity is inhibited by Stat1. (A) The effect of Stat 1 on the promoter activation by Runx 2 or Smad1. Stat 1 inhibits Runx2 activation of the osteocalcin promoter, 1050 Oc-luc, but not Smad1 activation of $12 x G C C G-l u c$. Smadl is cotransfected with ALK3QD, a plasmid that encodes a constitutively active form of BMP-2 receptor. (B) DNA-binding activity of Runx2 is up-regulated in Stat ${ }^{-/-}$osteoblasts. Cell extracts of cultured osteoblasts derived from wild-type and Stat1 ${ }^{-/-}$mice were analyzed by EMSA using an oligonucleotide probe containing the binding sequence with Runx2. Wild-type and Stat1 ${ }^{-/-}$ osteoblasts expressed the same level of Runx2, but the DNA-binding activity of Runx2 was enhanced in Stat $1^{-/-}$osteoblasts. It is notable that Tyr 701 phosphorylation of Stat 1 (p-Stat 1$)$ is not detectable in this condition. BMP-2 increases the Runx 2 protein level in both wild-type and Stat $1^{-/-}$osteoblasts, but Runx2 activity was still enhanced in Stat $1^{-/-}$osteoblasts in the presence of BMP-2. AP-1 activity is not changed between these osteoblasts. $(C)$ Association of endogenous Runx2 with Stat 1 in primary osteoblasts. Cell extract was prepared from wild-type and Stat1 $1^{-/-}$osteoblasts and analyzed by immunoprecipitation with anti-Runx 2 antibody followed by blotting with anti-Stat 1 antibody. The complex formation was reduced in the presence of BMP-2.

blasts (Fig. 5B, upper panel). On the other hand, wildtype and Stat1 ${ }^{-/-}$osteoblasts showed no difference in the DNA-binding activity of AP-1, which is also involved in osteoblast differentiation (Fig. 5B, lower panel). These results in toto indicate that Stat 1 selectively interferes with the DNA-binding activity of Runx2.

Is the inhibitory effect of Stat1 on Runx2 activity dependent on its activation by phosphorylation? In the context of the signaling of IFNs and other cytokines, Stat 1 is activated by phosphorylation at Tyr 701. In addition, Ser 727 is also phosphorylated to enhance the transcriptional activity of Stat1 (Stark et al. 1998; O'Shea et al. 2002). Interestingly, the phosphorylation of Tyr 701 of Stat1 was barely detectable even in wild-type osteoblasts irrespective of BMP-2 stimulation, suggesting that the inhibition of Runx 2 activity by Stat 1 is independent of this phosphorylation (Fig. 5B; see also below). We also examined the phosphorylation of Ser 727, which is critical for its transcriptional activity (O'Shea et al. 2002); however, the serine phosphorylation of Stat1 was not detected with or without BMP-2 stimulation (data not shown), further suggesting that the effect of Stat1 on Runx 2 activity is exerted without the phosphorylationdependent activation of Stat1.

\section{Association of Stat1 with Runx2 in regulation of Runx2-mediated transcription}

To gain insights into the mechanism of how Stat 1 interferes with Runx2 activity, we investigated the association between Stat1 and Runx2. As shown in Figure 5C, immunoprecipitation and immunoblotting analyses re- vealed that endogenous Stat 1 interacts with endogenous Runx2 in primary osteoblasts. Interestingly, the interaction becomes weaker upon BMP-2 stimulation of the osteoblasts, in the face of an increase in total Runx2 protein level (Fig. 5C).

To determine the region of the Stat1 protein responsible for its association with Runx2, we constructed two deletion mutants (Stat $1 \Delta \mathrm{C} 1$ and Stat $1 \Delta \mathrm{C} 2$ ) lacking the C-terminal region containing $\mathrm{TAD}$ and $\mathrm{SH} 2$ (Fig. 6B; O'Shea et al. 2002). These proteins as well as Runx2 were epitope-tagged (see Materials and Methods for the details), and the intermolecular association was examined by transiently expressing them in $293 \mathrm{~T}$ cells. We found that both $\mathrm{C}$ terminus mutants still associate with Runx2 (Fig. 6A, left). We then examined the Stat1 mutant, Stat $1 \Delta S S$, lacking the DNA-binding domain (DBD) and the linker domain (S316-S606; Wu et al. 2002), and found that this mutant does not associate with Runx2 (Fig. 6A, right). Thus, Stat 1 requires the region containing DBD and the linker domain to associate with Runx2.

We further examined the region of Runx 2 that is required for its association with Stat1, by using a similar coexpression assay. The Runx2 mutant lacking the QA domain, Runx2 $\Delta$ QA (Thirunavukkarasu et al. 1998), can associate with Stat1, but the QA domain alone (Runx2QA) cannot associate with it (Fig. 6C). On the other hand, the Runx2 mutant lacking the QA and PST domains (Runx2runt) can bind with Stat1 (Fig. 6C). These observations suggest that the PST domain is dispensable for the association and that the runt domain may be responsible for its association with Stat 1. 
Kim et al.

Figure 6. Physical interaction of Stat 1 with Runx2 interferes with Runx2 activity. (A) Association of Statl mutants with Runx2. C-terminal domains are dispensable, but the $\mathrm{DBD} /$ linker domain is essential for interaction with Runx2. (IP) Immunoprecipitation; (IB) immunoblotting. (B) A schematic of deletion mutants of Stat 1 and Runx2. (C) Association of Runx2 mutants with Stat1. QA and PST domains are dispensable, but the remainder containing the runt domain is essential for interaction with Stat1. (n.s.) Nonspecific. (D) The inhibitory effect of Stat 1 on Runx 2 activity is phosphorylation-independent. The effect of Stat 1 and Stat1CYF, the phosphorylationdeficient form of Stat1, on the Runx2-dependent activation of the osteocalcin promoter was examined in a transient assay in 293 cells. Stat 1 and Stat1CYF equally have an inhibitory action on Runx 2 activity. The inhibitory effect of Stat 1 is reduced when it is tyrosine-phosphorylated by IFN- $\gamma$ (see Fig. 5E). (E) Association of Stat1 and Stat1CYF with Runx2 and the effect of IFN- $\gamma$ on their phosphorylation and interaction. Stat 1 and Stat1CYF equally associate with Runx2 in 293 T cells. Forty-eight hours after transfection, the cell lysate was prepared from cells cultured in the same condition for the luciferase assay (see Fig. 5D). IFN- $\gamma$-induced phosphorylation of Tyr 701 is observed in wild-type Stat1, but not in Stat1CYF. The interaction with Runx 2 was reduced when Stat 1 was phosphorylated by IFN- $\gamma$.
A

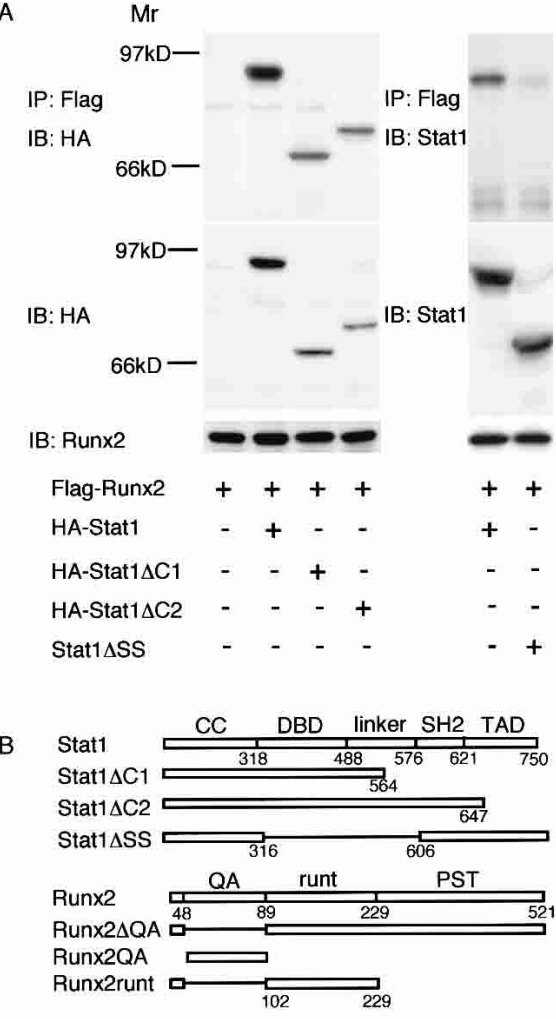

D

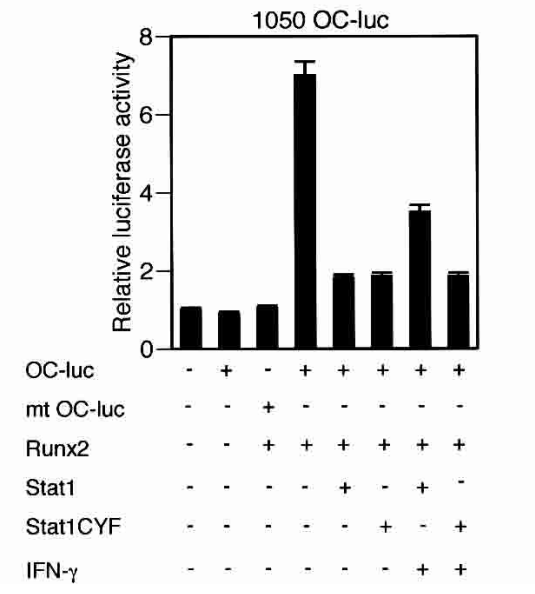

C

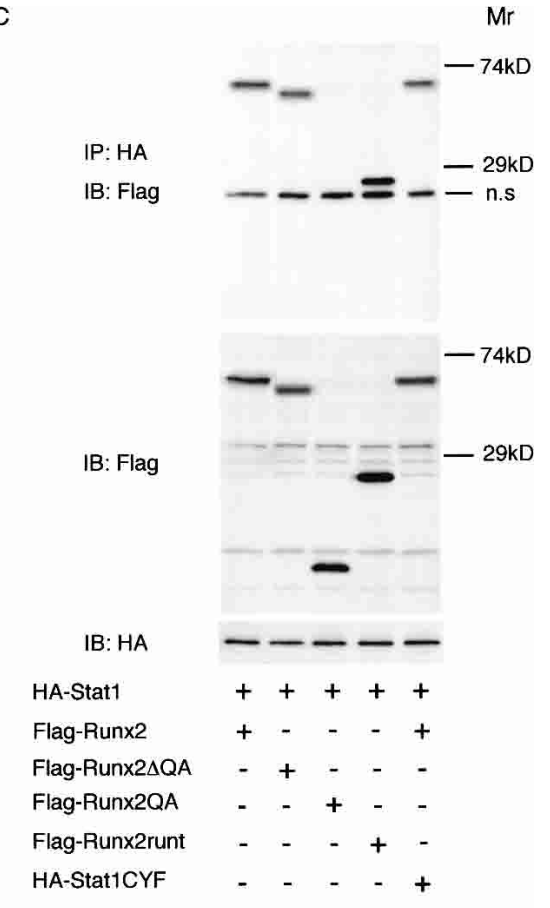

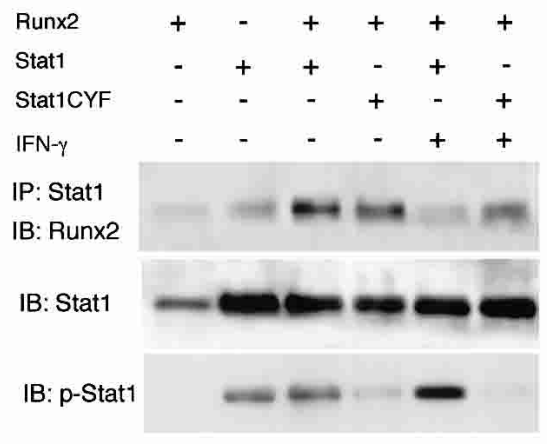

Phosphorylation of Stat1 and its inhibitory effect on Runx2 activity

Stat1 undergoes dimerization upon phosphorylation of Tyr 701 and translocates to the nucleus. To investigate the effect of this phosphorylation on Stat1 inhibition of Runx2, we used a mutant form of Stat1 in which Tyr 701 is converted to phenylalanine (Stat1CYF; Chatterjee-Kishore et al. 2000). As shown in Figure 6D, the overexpression of Stat1CYF inhibited the Runx2-dependent activation of the osteocalcin promoter, as efficiently as wild-type Stat1. Indeed, Stat1CYF can still interact with Runx2 (Fig. 6C,E), lending further support to the notion that the inhibitory function of Stat1 on Runx2 activity is dependent on its interaction with Runx2, but not on its phosphorylation.
Does activation of Statl affect its interaction with Runx2? Interestingly, IFN- $\gamma$ stimulation partially relieved the suppressive effect of Stat1 on the Rnux2-dependent activation of the osteocalcin promoter (Fig. 6D) and also weakened the Stat1 interaction with Runx2 (Fig. 6E). On the other hand, this IFN- $\gamma$ effect on Stat1CYF was not observed (Fig. 6D,E). These results suggest that Stat1 activation, which leads to its dimerization and nuclear translocation, results in the loss of its ability to interact with Runx2. Consistently, we observed that IFN- $\gamma$ enhances in vitro osteoblast differentiation (H. Takayanagi, unpubl.). Although the physiological significance of these observations in bone remodeling is not clear at present, they lend further support to the idea that Stat 1 inhibits Runx2 activity in its transcriptionally latent form. 


\section{Inhibition of nuclear translocation of Runx2 by Stat1}

The above observations led us to hypothesize that unphosphorylated Stat1 residing in the cytoplasm associates with Runx2 and interferes with its nuclear translocation. As shown in Figure 7A, immunostaining analysis revealed that Runx 2 efficiently undergoes nuclear translocation when it is expressed in $293 \mathrm{~T}$ cells, but that the majority of Runx 2 remains in the cytoplasm when Stat 1 is coexpressed, an observation consistent with the results in Figure 6. This concept is further supported by the results of immunoblot analysis (Fig. 7B), which indicate that Runx2 is mainly detectable in the nuclear fraction in the absence of coexpressed Stat 1 , but this equilibrium is shifted to the cytoplasm in the presence of Stat1. In view of these results indicating an enhanced interaction between Stat1 and Runx2 upon cotransfection of the cDNAs encoding these two factors, it is likely that this intermolecular interaction is direct, although this issue needs to be clarified further.
Finally, we examined Runx2 nuclear localization in primary osteoblasts derived from the wild-type and Stat $1^{-/-}$mice. Consistent with the EMSA data showing the enhanced DNA-binding activity of Runx2 in Stat ${ }^{-/-}$ cells (Fig. 5B), Runx2 nuclear translocation is more prominent in Stat1 ${ }^{-/}$osteoblasts than in wild-type osteoblasts (Fig. 7C), suggesting that Runx2 nuclear localization is regulated by the transcriptionally latent form of Stat 1 in the cytoplasm.

\section{Discussion}

\section{Stat1 as a negative regulator of bone formation}

Skeletal homeostasis is controlled by the intricate coordination of constituent cells including chondrocytes, osteoblasts, and osteoclasts (Karsenty and Wagner 2002). We previously showed that Stat 1 mediates the suppressive effect of IFNs on the differentiation of osteoclasts (Takayanagi et al. 2002b). In fact, excessive osteoclasto-
A

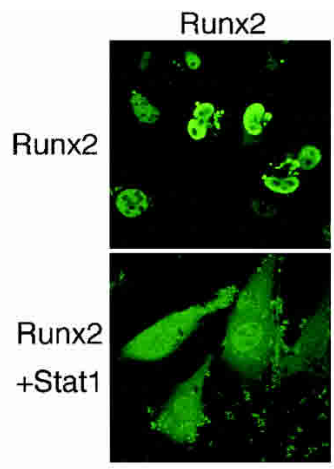

Stat1
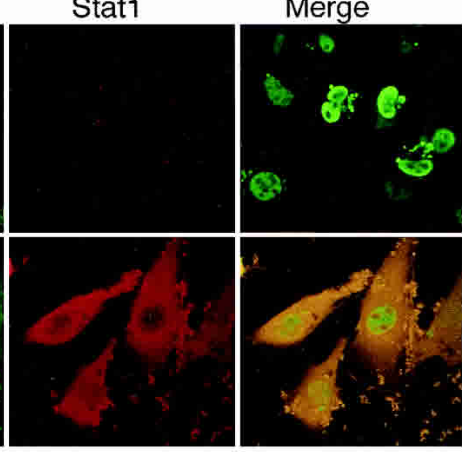

B

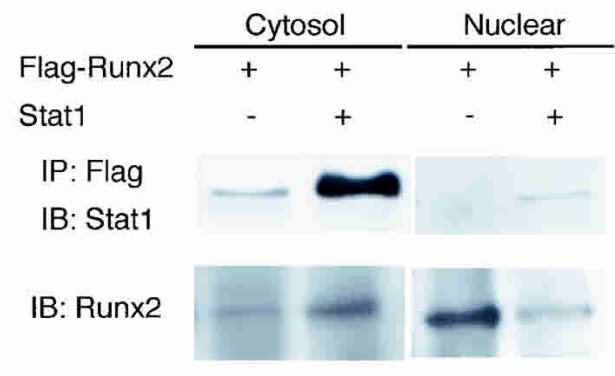

C

Runx2

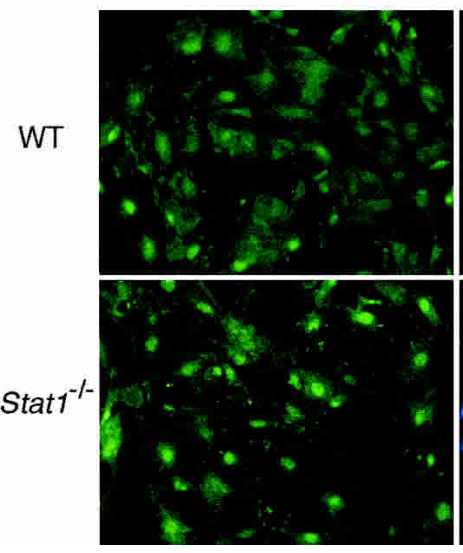

DAPI

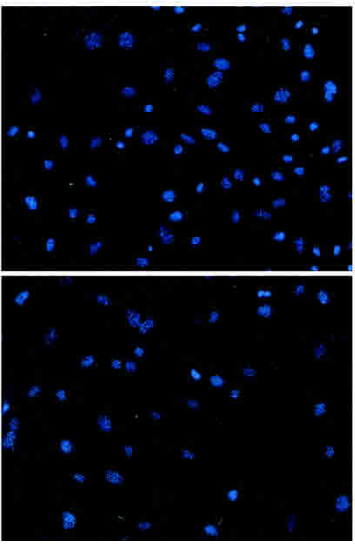

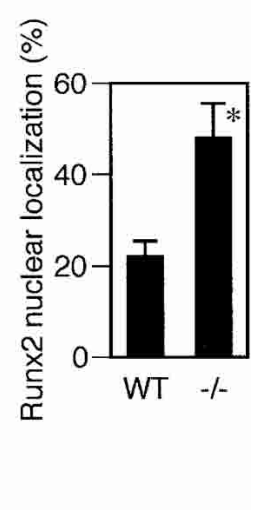

Figure 7. Cytoplasmic sequestration of Runx2 by Stat1. (A) Localization of Runx2 with or without coexpression of Stat 1 in 293T cells. Immunostaining shows that Runx2 efficiently undergoes nuclear translocation when overexpressed in $293 \mathrm{~T}$ cells, but the nuclear localization was inhibited by coexpression of Stat1, which is located mainly in the cytoplasm. $(B)$ Detection of Runx2 protein in cytosolic and nuclear fractions by immunoblotting. If Runx2 is solely overexpressed in $293 \mathrm{~T}$ cells, most of the Runx 2 protein is detected in the nuclear fraction. Under this condition, the association of Runx 2 with endogenous Stat1 is detected in the cytoplasm at a low level. When Stat 1 is coexpressed, a great amount of Stat 1 interacts with Runx 2 in the cytoplasm, resulting in the sequestration of Runx2 in the cytoplasm. $(C)$ Nuclear localization of Runx2 in wild-type and Stat1 $1^{-/-}$osteoblasts. The percentage of cells that exhibit nuclear translocation of Runx2 is significantly higher in Stat1 ${ }^{-/}$osteoblasts than in wild-type osteoblasts. 
genesis, similar to that observed in IFNAR $1^{-/-}$mice, was also found in Stat ${ }^{-/-}$mice. Interestingly, however, bone mass is increased in the Stat $1^{-/-}$mice, revealing that Stat 1 also plays a critical role in the inhibition of Runx2mediated osteoblast differentiation. The net increase in bone mass suggests that the function of Stat1 in osteoblasts dominates over that in osteoclasts in vivo. It has been reported that Stat1 plays a critical role in the FGFmediated suppression of chondrocyte proliferation in disease conditions such as achondroplasia (Sahni et al. 1999, 2001). Our results showing the normal epiphyseal growth plate and longitudinal bone length in the adult Stat $1^{-1-}$ mice suggest that physiological chondrocyte proliferation is not markedly enhanced in the absence of Stat1.

\section{Regulation of Runx2 by Stat1 at a postnatal stage}

Runx2 has been identified as the central transcription factor for bone formation, but how its function is regulated remains largely unknown. We have shown that the loss of inhibition of Runx 2 activity by Stat 1 results in increased bone mass in the adult Stat $1^{-/-}$mice without affecting bone formation during the developmental period, suggesting that Stat1 is selectively involved in the Runx2 regulation in bone remodeling at the postnatal stage. Since it is currently unknown how Runx2 is regulated during the development of the skeletal system, further studies are required to clarify the detailed mechanism of the temporal and spatial regulation of Runx 2 for the normal development and homeostatic regulation of the skeletal system.

It has been reported that Runx2 overexpression in osteoblasts by the type I collagen promoter inhibits osteoblast differentiation at a late stage (Liu et al. 2001). Therefore, sustained Runx2 expression in the late stage of osteoblast differentiation may inhibit bone formation, and Runx2 expression should be strictly controlled in a stage-dependent manner during osteoblast differentiation (Komori 2002). In this regard, Stat 1 deficiency does not modify Runx2 expression, but increases the activity of Runx2, whose expression is physiologically controlled. Thus, Stat $1^{-/}$mice may provide an interesting model in that the temporal Runx2 expression is normal but its activity is enhanced.

\section{Involvement of BMP-2 in the regulation of Runx2 by Stat1}

BMP-2 is a potent inducer of ectopic bone formation, but it remains to be elucidated whether BMP- 2 is essential for osteoblast differentiation in vivo (Karsenty and Wagner 2002). In this study, we show that osteoblast differentiation is enhanced in Stat $1^{-/-}$cells even in the presence of exogenous BMP-2. Enhanced osteoblast differentiation is also observed in the absence of exogenous BMP-2, but it remains to be clarified how BMP-2 contributes to the in vivo phenotype of Stat ${ }^{-/-}$mice. Based on the fact that endogenous BMP-2 expression is detectable in cultured osteoblasts and BMP-2 induces and activates Runx2 (Zhang et al. 2000; Ito and Miyazono
2003), we propose that the enhanced response of osteoblasts to BMP-2 contributes, at least in part, to the excessive osteoblast differentiation in Stat ${ }^{-/-}$mice. It is also interesting that BMP-2 induces Runx2 dissociation from Stat1 (Fig. 5C). Although the detailed mechanism underlying this phenomenon remains to be clarified, we infer that Runx2 dissociation from Stat1 upon BMP-2 stimulation is a consequence of Runx2 interaction with BMP-2-induced transcription factors, most likely the Smad proteins. In fact, Smad1, Smad5, and Smad8 are known to be activated by BMP-2, and these factors, together with Smad4, interact with Runx2 to induce the transcriptional program for osteoblast differentiation (Zhang et al. 2000). In other words, the Runx2 dissociation is a consequence of the swapping of the partner of Runx2 before and after BMP-2 stimulation. This issue obviously needs to be addressed further in a future study.

\section{Stat1 as a cytoplasmic attenuator of Runx2}

The mode of action of Stat 1 is unique in that it interferes with Runx2 in the cytoplasm in its transcriptionally latent form. It has been shown previously that Stat1 functions in the nucleus in the absence of phosphorylation at Tyr 701 to mediate the constitutive expression of genes that respond to activated Stat1 (in the context of IFN signaling; Chatterjee-Kishore et al. 2000). On the other hand, our results indicate that Stat 1 exerts its inhibitory effect on Runx2 mainly, if not exclusively, in the cytoplasm, although the possibility that the latent Stat1 additionally functions in the nucleus to interfere with Runx2 cannot be rigorously ruled out. Further work will be required to elucidate the precise inhibitory mechanism of Runx2 nuclear localization by Stat1. It is possible that Runx2 binding with Stat1 leads to the conformational change of Runx2, thus concealing the nuclear localization signal (NLS) domain. Supporting this view are the previous report that the Runx 2 NLS is adjacent to the runt domain (Thirunavukkarasu et al. 1998) and our result suggesting that the runt domain may interact with Stat1. Because the DNA-binding activity but not the protein level of Runx2 is increased in osteoblasts from Stat $1^{-/-}$mice, we infer that Stat1-associated Runx2 is also inactive in terms of its DNA-binding activity.

The inhibitory effect of Stat1 on Runx2 activity is unique in that a given transcription factor, in its latent form, regulates the function of another transcription factor in the cytoplasm. Collectively, we propose that Stat1 functions as a cytoplasmic attenuator of Runx2 in osteoblast differentiation. To date, most drug therapies for osteopenic diseases aim at the suppression of osteoclastic bone resorption. This study may provide an alternative approach to the modulation of bone formation through intervention of Stat1.

\section{Materials and methods}

Mice and bone analysis

The Stat1 $^{-/-}$and IRF-9 -/- $^{-/}$mice have been described (Kimura et al. 1996; Meraz et al. 1996). Mutant mice were backcrossed with 
C57BL/6 mice more than 10 times, and subjected to histomorphometric and microradiographic examinations as described (Takayanagi et al. 2002b). All mice were born and kept under pathogen-free conditions, and showed no abnormality in growth rate or body weight. Bone mineral density was determined by the dual energy X-ray absorptiometry (DXA) method using DCS-600R (Aloka). Bone mechanical strength testing was performed using a three-point bending method with Autograph AG2000-E (Shimazu). Biochemical parameters were determined from the load-deformation curve as described (Tanizawa et al. 2000). The maximum load to failure (N) indicated the magnitude of the load that caused fracture, and the energy resorption (N. $\mathrm{mm}$ ) was determined by the area under the load-deformation curve up to the maximum load point. All data are shown as mean \pm S.E. $(n=6)$. Statistical analysis was performed using one-way ANOVA or Student's $t$-test throughout the paper (n.s. denotes not significant; ${ }^{*}$ and ${ }^{* *}$ indicate $p<0.05$ and $p<0.01$, respectively).

\section{In vitro osteoblast differentiation assay}

Osteoblasts were isolated from the calvarial bone of newborn $(3-5 \mathrm{~d})$ mice by enzymatic digestion in $\alpha$-MEM with $0.1 \%$ collagenase and $0.2 \%$ dispase as described (Ogata et al. 2000), and were cultured in $\alpha$-MEM with $10 \%$ FBS. After $2 \mathrm{~d}$, cells were reseeded $\left(5 \times 10^{4}\right.$ cells per well in a 24 -well dish) and cultured in $\alpha$-MEM with $10 \%$ FBS containing $50 \mu \mathrm{g} / \mathrm{mL}$ ascorbic acid, 10 $\mathrm{mM} \beta$-glycerophosphate, and $10 \mathrm{nM}$ dexamethasone for the osteoblast differentiation assay. After $7 \mathrm{~d}$, ALP activity was assayed, and after $21 \mathrm{~d}$, bone nodule formation was assayed by alizarin red staining as described (Ogata et al. 2000). After $14 \mathrm{~d}$, we extracted mRNA from cultured osteoblasts with Sepasol (Nacalai), and performed semiquantitative reverse transcriptase PCR (RT-PCR) or RNA blotting analysis of osteoblast-specific genes as previously described (Ducy et al. 1997). PCR primers are as follows: ALP (sense, 5'-GACTGGTACTCGGATAAC GAGATGC-3'; antisense, 5'-TGCGGTTCCAGACATAGTG G-3') and GAPDH (sense, 5' -AGGAGCGAGACCCCACTAAC3'; antisense, 5'-TGCCAGTGAGCTTCCCGTTC-3').

\section{Retroviral gene transfer}

Packaging and inoculation of retrovirus vectors, $\mathrm{pBabe}$ or $\mathrm{pBabe}$ Statl [a gift from D. Stoiber (Institute of Pharmacology, University of Vienna, Vienna, Austria) and V. Sexl (Institute of Pharmacology, University of Vienna, Vienna, Austria)] were performed as described previously (Takayanagi et al. 2002b). Osteoblasts $\left(1 \times 10^{5}\right.$ cells in a well of a 6-well plate) were inoculated with retroviruses and cultured in $\alpha$-MEM with $10 \%$ FBS. After $2 \mathrm{~d}$ of culture, the medium was changed to $\alpha$-MEM with $10 \%$ FBS containing $50 \mu \mathrm{g} / \mathrm{mL}$ ascorbic acid, $10 \mathrm{mM} \beta$-glycerophosphate, and $10 \mathrm{nM}$ dexamethasone. After $14 \mathrm{~d}$ of culture, cells were fixed for ALP assay or analyzed by immunoblotting.

\section{RNase protection assay}

For the RNase protection assay for the mRNAs of the BMP family members, we extracted total RNA from osteoblasts cultured for $7 \mathrm{~d}$ as described above, and analyzed the mRNA using an RNase protection assay kit (Pharmingen) according to the manufacturer's protocol. When we analyzed the osteoblast differentiation in the presence of recombinant BMP-2, we added BMP-2 to the culture of osteoblasts at a concentration of 100 $\mathrm{ng} / \mathrm{mL}$ throughout the culture period.

\section{Luciferase assay}

We transfected the reporter plasmid containing the osteocalcin promoter, 1050Oc-luc, or mutated (mt) 1050Oc-luc (Javed et al.
1999), and the Runx2 expression vector, pEF-BOS- $\alpha$ A1, to $293 \mathrm{~T}$ cells with or without the Stat1 expression vector, pSG91, using FuGENE6 (Roche). We similarly transfected 12xGCCG-luc, ALK3QD, and pcDNA3-Smad1 as described (Yoshida et al. $2000)$ with or without Stat 1 . When necessary, IFN- $\gamma(100 \mathrm{U} / \mathrm{mL})$ was added $36 \mathrm{~h}$ after transfection. The luciferase assay was performed $48 \mathrm{~h}$ after transfection as described previously (Takayanagi et al. 2002a). All data are expressed as mean \pm S.E. $(n=5)$.

\section{EMSA}

After $7 \mathrm{~d}$ of culture of osteoblasts derived from WT or Stat1 ${ }^{-/}$ mice, proteins were extracted with sonication method using lysis buffer [20 mM HEPES at pH 7.9, $50 \mathrm{mM} \mathrm{NaCl}, 10 \mathrm{mM}$ EDTA, $10 \%(\mathrm{v} / \mathrm{v})$ glycerol, $10 \mathrm{mM}$ sodium molybdate, $10 \mathrm{mM}$ ortho vanadate, $100 \mathrm{mM}$ sodium fluoride, $0.1 \%$ (v/v) NP-40, 1 $\mathrm{mM}$ DTT, $100 \mu \mathrm{g} / \mathrm{mL}$ leupeptin, and $0.5 \mathrm{mM}$ APMSF]. Then 35 $\mu \mathrm{g}$ of proteins was used to bind with the $\left[\gamma^{3}{ }^{32} \mathrm{P}\right] \mathrm{ATP}-\mathrm{labeled}$ oligonucleotide probe containing the binding sequence with Runx2 as described (Kagoshima et al. 1996) or with AP-1 (Jochum et al. 2000). Supershift was performed with a mouse antiRunx2 monoclonal antibody (a gift from Y. Ito, Institute of Molecular and Cell Biology, National University of Singapore, Singapore).

\section{Immunoprecipitation and immunoblot analysis}

Cell extracts were harvested from primary osteoblasts or 293T cells transfected with indicated expression vectors for $48 \mathrm{~h}$ in TNE buffer $(10 \mathrm{mM}$ Tris- $\mathrm{HCl}, 150 \mathrm{mM} \mathrm{NaCl}, 1 \mathrm{mM}$ EDTA, $1 \%$ NP-40, $2 \mathrm{mM} \mathrm{Na}_{3} \mathrm{VO}_{4}, 10 \mathrm{mM} \mathrm{NaF}$, and $10 \mu \mathrm{g} / \mathrm{mL}$ aprotinin). Cell extracts were incubated with $1 \mu \mathrm{g}$ of anti-Runx2, anti-Stat 1 (p84/91; Santa Cruz) or anti-Flag (Sigma) antibodies at $4^{\circ} \mathrm{C}$ for 1 $\mathrm{h}$. Immune complexes were recovered with protein G Sepharose (Amersham), subjected to SDS-PAGE, and blotted with indicated antibodies. Nuclear and cytosolic extracts were prepared as described (Thirunavukkarasu et al. 1998). For immunoblotting, we used anti-HA antibody (Santa Cruz), anti-phosphoStat1 (Tyr 701; New England Biolab), and Ser 727 antibodies (Upstate). HA-Stat $1 \Delta \mathrm{C}$ mutants were constructed by deleting the $\mathrm{C}$ terminus region of HA-Stat1 (a gift of X.Y. Fu) as described in Figure 6B. Stat1CYF (a gift of X.Y. Fu, Department of Pathology, Yale University School of Medicine, New Haven, CT) and Stat1 $\Delta$ SS (a gift of Y. Eugene Chin, Department of Pathology and Laboratory Medicine, Brown University School of Medicine, Providence, RI) have been described (Wu et al. 2002). The construction strategy of Runx 2 mutants has been previously described (Thirunavukkarasu et al. 1998).

\section{Immunofluorescence staining}

$293 \mathrm{~T}$ cells were fixed $24 \mathrm{~h}$ after transfection in $4 \%$ paraformaldehyde for $20 \mathrm{~min}$ and treated with $0.2 \%$ Triton $\mathrm{X}$ for $5 \mathrm{~min}$. Primary osteoblasts were fixed $7 \mathrm{~d}$ after incubation in $\alpha$-MEM containing $50 \mu \mathrm{g} / \mathrm{mL}$ ascorbic acid, $10 \mathrm{mM} \beta$-glycerophosphate, and $10 \mathrm{nM}$ dexamethasone. Cells were sequentially incubated in $5 \% \mathrm{BSA} / \mathrm{PBS}$ for $30 \mathrm{~min}, 2 \mu \mathrm{g} / \mathrm{mL}$ anti-Runx 2 monoclonal antibody or anti-Stat 1 polyclonal antibody in PBST for $60 \mathrm{~min}$, and then $4 \mu \mathrm{g} / \mathrm{mL}$ Alexa 488 or 546-labeled anti-mouse or antirabbit IgG antibody (Molecular Probe) for $60 \mathrm{~min}$.

\section{Acknowledgments}

We thank R.D. Schreiber for the mutant mice, H. Murayama and Kureha Chemical Industries for technical assistance, and 
Yamanouchi Pharmaceuticals for providing recombinant BMP2. We also appreciate T. Komori, T. Furuichi, Y. Ito, K. Ito, J.B. Lian, X.Y. Fu, M. Kitagawa, G. Watanabe, K. Miyazono, K. Imamura, D. Stoiber, and V. Sexl for mice, materials, and discussion; and P.E. Bialek, A. Suematsu, M. Urushibara, A. Takaoka, K. Honda, S. Kano, and I. Kawai for technical assistance and discussion. This work was supported in part by a grant for Advanced Research on Cancer from the Ministry of Education, Culture, Sports, Science, and Technology (MEXT) of Japan; a grant from PRESTO, Japan Science and Technology Corporation (JST); Grants-in-Aid for Scientific Research from MEXT and JSPS; Health Sciences Research Grants from the Ministry of Health, Labour and Welfare of Japan; grants of the Virtual Research Institute of Aging of Nippon Boehringer Ingelheim; and a grant from Japan Orthopaedics and Traumatology Foundation.

The publication costs of this article were defrayed in part by payment of page charges. This article must therefore be hereby marked "advertisement" in accordance with 18 USC section 1734 solely to indicate this fact.

\section{References}

Bellido, T., Borba, V.Z., Roberson, P., and Manolagas, S.C. 1997. Activation of the Janus kinase/STAT (signal transducer and activator of transcription) signal transduction pathway by interleukin-6-type cytokines promotes osteoblast differentiation. Endocrinology 138: 3666-3676.

Chatterjee-Kishore, M., Wright, K.L., Ting, J.P., and Stark, G.R. 2000. How Stat 1 mediates constitutive gene expression: A complex of unphosphorylated Stat1 and IRF1 supports transcription of the LMP2 gene. EMBO J. 19: 4111-4122.

Daluiski, A., Engstrand, T., Bahamonde, M.E., Gamer, L.W., Agius, E., Stevenson, S.L., Cox, K., Rosen, V., and Lyons, K.M. 2001. Bone morphogenetic protein-3 is a negative regulator of bone density. Nat. Genet. 27: 84-88.

Deng, C., Wynshaw-Boris, A., Zhou, F., Kuo, A., and Leder, P. 1996. Fibroblast growth factor receptor 3 is a negative regulator of bone growth. Cell 84: 911-921.

Ducy, P., Zhang, R., Geoffroy, V., Ridall, A.L., and Karsenty, G. 1997. Osf2/Cbfa1: A transcriptional activator of osteoblast differentiation. Cell 89: 747-754.

Ducy, P., Schinke, T., and Karsenty, G. 2000. The osteoblast: A sophisticated fibroblast under central surveillance. Science 289: $1501-1504$.

Heldin, C.H., Miyazono, K., and ten Dijke, P. 1997. TGF- $\beta$ signalling from cell membrane to nucleus through SMAD proteins. Nature 390: 465-471.

Ito, Y. and Miyazono, K. 2003. RUNX transcription factors as key targets of TGF- $\beta$ superfamily signaling. Curr. Opin. Genet. Dev. 13: 43-47.

Javed, A., Gutierrez, S., Montecino, M., van Wijnen, A.J., Stein, J.L., Stein, G.S., and Lian, J.B. 1999. Multiple Cbfa/AML sites in the rat osteocalcin promoter are required for basal and vitamin D-responsive transcription and contribute to chromatin organization. Mol. Cell. Biol. 19: 7491-7500.

Jochum, W., David, J.P., Elliott, C., Wutz, A., Plenk Jr., H., Matsuo, K., and Wagner, E.F. 2000. Increased bone formation and osteosclerosis in mice overexpressing the transcription factor Fra-1. Nat. Med. 6: 980-984.

Kagoshima, H., Akamatsu, Y., Ito, Y., and Shigesada, K. 1996. Functional dissection of the $\alpha$ and $\beta$ subunits of transcription factor PEBP2 and the redox susceptibility of its DNA binding activity. J. Biol. Chem. 271: 33074-33082.

Karsenty, G. and Wagner, E.F. 2002. Reaching a genetic and molecular understanding of skeletal development. Dev. Cell 2: 389-406.

Kimura, T., Kadokawa, Y., Harada, H., Matsumoto, M., Sato, M., Kashiwazaki, Y., Tarutani, M., Tan, R.S., Takasugi, T., Matsuyama, T., et al. 1996. Essential and non-redundant roles of p48 (ISGF3 $\gamma$ ) and IRF-1 in both type I and type II interferon responses, as revealed by gene targeting studies. Genes Cells 1: 115-124.

Komori, T. 2002. Runx2, a multifunctional transcription factor in skeletal development. J. Cell Biochem. 87: 1-8.

Komori, T., Yagi, H., Nomura, S., Yamaguchi, A., Sasaki, K., Deguchi, K., Shimizu, Y., Bronson, R.T., Gao, Y.H., Inada, M., et al. 1997. Targeted disruption of Cbfal results in a complete lack of bone formation owing to maturational arrest of osteoblasts. Cell 89: 755-764.

Kong, Y.Y., Feige, U., Sarosi, I., Bolon, B., Tafuri, A., Morony, S., Capparelli, C., Li, J., Elliott, R., McCabe, S., et al. 1999. Activated $\mathrm{T}$ cells regulate bone loss and joint destruction in adjuvant arthritis through osteoprotegerin ligand. Nature 402: 304-309.

Lee, K.S., Kim, H.J., Li, Q.L., Chi, X.Z., Ueta, C., Komori, T., Wozney, J.M., Kim, E.G., Choi, J.Y., Ryoo, H.M., et al. 2000. Runx 2 is a common target of transforming growth factor $\beta 1$ and bone morphogenetic protein 2, and cooperation between Runx2 and Smad5 induces osteoblast-specific gene expression in the pluripotent mesenchymal precursor cell line C2C12. Mol. Cell. Biol. 20: 8783-8792.

Liu, W., Toyosawa, S., Furuichi, T., Kanatani, N., Yoshida, C., Liu, Y., Himeno, M., Narai, S., Yamaguchi, A., and Komori, T. 2001. Overexpression of Cbfa1 in osteoblasts inhibits osteoblast maturation and causes osteopenia with multiple fractures. J. Cell Biol. 155: 157-166.

Manolagas, S.C. 2000. Birth and death of bone cells: Basic regulatory mechanisms and implications for the pathogenesis and treatment of osteoporosis. Endocr. Rev. 21: 115-137.

Massague, J. 2000. How cells read TGF- $\beta$ signals. Nat. Rev. Mol. Cell. Biol. 1: 169-178.

Meraz, M.A., White, J.M., Sheehan, K.C., Bach, E.A., Rodig, S.J., Dighe, A.S., Kaplan, D.H., Riley, J.K., Greenlund, A.C., Campbell, D., et al. 1996. Targeted disruption of the Stat1 gene in mice reveals unexpected physiologic specificity in the JAK-STAT signaling pathway. Cell 84: 431-442.

Ogata, N., Chikazu, D., Kubota, N., Terauchi, Y., Tobe, K., Azuma, Y., Ohta, T., Kadowaki, T., Nakamura, K., and Kawaguchi, H. 2000. Insulin receptor substrate-1 in osteoblast is indispensable for maintaining bone turnover. J. Clin. Invest. 105: 935-943.

Olsen, B.R., Reginato, A.M., and Wang, W. 2000. Bone development. Annu. Rev. Cell. Dev. Biol. 16: 191-220.

O'Shea, J.J., Gadina, M., and Schreiber, R.D. 2002. Cytokine signaling in 2002: New surprises in the Jak/Stat pathway. Cell 109 Suppl: S121-S131.

Otto, F., Thornell, A.P., Crompton, T., Denzel, A., Gilmour, K.C., Rosewell, I.R., Stamp, G.W., Beddington, R.S., Mundlos, S., Olsen, B.R., et al. 1997. Cbfal, a candidate gene for cleidocranial dysplasia syndrome, is essential for osteoblast differentiation and bone development. Cell 89: 765-771.

Rodan, G.A. and Martin, T.J. 2000. Therapeutic approaches to bone diseases. Science 289: 1508-1514.

Rousseau, F., Bonaventure, J., Legeai-Mallet, L., Pelet, A., Rozet, J.M., Maroteaux, P., Le Merrer, M., and Munnich, A. 1994. Mutations in the gene encoding fibroblast growth factor receptor-3 in achondroplasia. Nature 371: 252-254.

Sabatakos, G., Sims, N.A., Chen, J., Aoki, K., Kelz, M.B., Amling, M., Bouali, Y., Mukhopadhyay, K., Ford, K., Nestler, E.J., et al. 2000. Overexpression of $\Delta$ FosB transcription fac- 
tor(s) increases bone formation and inhibits adipogenesis. Nat. Med. 6: 985-990.

Sahni, M., Ambrosetti, D.C., Mansukhani, A., Gertner, R., Levy, D., and Basilico, C. 1999. FGF signaling inhibits chondrocyte proliferation and regulates bone development through the STAT-1 pathway. Genes \& Dev. 13: 1361-1366.

Sahni, M., Raz, R., Coffin, J.D., Levy, D., and Basilico, C. 2001. STAT1 mediates the increased apoptosis and reduced chondrocyte proliferation in mice overexpressing FGF2. Development 128: 2119-2129.

Stark, G.R., Kerr, I.M., Williams, B.R., Silverman, R.H., and Schreiber, R.D. 1998. How cells respond to interferons. Annu. Rev. Biochem. 67: 227-264.

Su, W.C., Kitagawa, M., Xue, N., Xie, B., Garofalo, S., Cho, J., Deng, C., Horton, W.A., and Fu, X.Y. 1997. Activation of Stat 1 by mutant fibroblast growth-factor receptor in thanatophoric dysplasia type II dwarfism. Nature 386: 288-292.

Takayanagi, H., Iizuka, H., Juji, T., Nakagawa, T., Yamamoto, A., Miyazaki, T., Koshihara, Y., Oda, H., Nakamura, K., and Tanaka, S. 2000a. Involvement of receptor activator of nuclear factor $\kappa \mathrm{B}$ ligand/osteoclast differentiation factor in osteoclastogenesis from synoviocytes in rheumatoid arthritis. Arthritis Rheum. 43: 259-269.

Takayanagi, H., Ogasawara, K., Hida, S., Chiba, T., Murata, S., Sato, K., Takaoka, A., Yokochi, T., Oda, H., Tanaka, K., et al. 2000b. T-cell-mediated regulation of osteoclastogenesis by signalling cross-talk between RANKL and IFN- $\gamma$. Nature 408: 600-605.

Takayanagi, H., Kim, S., Koga, T., Nishina, H., Isshiki, M., Yoshida, H., Saiura, A., Isobe, M., Yokochi, T., Inoue, J., et al. 2002a. Induction and activation of the transcription factor NFATc1 (NFAT2) integrate RANKL signaling in terminal differentiation of osteoclasts. Dev. Cell 3: 889-901.

Takayanagi, H., Kim, S., Matsuo, K., Suzuki, H., Suzuki, T., Sato, K., Yokochi, T., Oda, H., Nakamura, K., Ida, N., et al. 2002b. RANKL maintains bone homeostasis through c-Fosdependent induction of interferon- $\beta$. Nature 416: 744-749.

Takayanagi, H., Kim, S., and Taniguchi, T. 2002c. Signaling crosstalk between RANKL and interferons in osteoclast differentiation. Arthritis Res. 4 Suppl 3: S227-S232.

Taniguchi, T., Ogasawara, K., Takaoka, A., and Tanaka, N. 2001. IRF family of transcription factors as regulators of host defense. Annu. Rev. Immunol. 19: 623-655.

Tanizawa, T., Yamaguchi, A., Uchiyama, Y., Miyaura, C., Ikeda, T., Ejiri, S., Nagal, Y., Yamato, H., Murayama, H., Sato, M., et al. 2000. Reduction in bone formation and elevated bone resorption in ovariectomized rats with special reference to acute inflammation. Bone 26: 43-53.

Teitelbaum, S.L. 2000. Bone resorption by osteoclasts. Science 289: $1504-1508$.

Thirunavukkarasu, K., Mahajan, M., McLarren, K.W., Stifani, S., and Karsenty, G. 1998. Two domains unique to osteoblast-specific transcription factor Osf2/Cbfa1 contribute to its transactivation function and its inability to heterodimerize with Cbf $\beta$. Mol. Cell. Biol. 18: 4197-4208.

Wang, E.A., Rosen, V., D'Alessandro, J.S., Bauduy, M., Cordes, P., Harada, T., Israel, D.I., Hewick, R.M., Kerns, K.M., LaPan, P., et al. 1990. Recombinant human bone morphogenetic protein induces bone formation. Proc. Natl. Acad. Sci. 87: 2220-2224.

Wu, T.R., Hong, Y.K., Wang, X.D., Ling, M.Y., Dragoi, A.M., Chung, A.S., Campbell, A.G., Han, Z.Y., Feng, G.S., and Chin, Y.E. 2002. SHP-2 is a dual-specificity phosphatase involved in Stat 1 dephosphorylation at both tyrosine and serine residues in nuclei. J. Biol. Chem. 277: 47572-47580.

Yamaguchi, A., Katagiri, T., Ikeda, T., Wozney, J.M., Rosen, V.,
Wang, E.A., Kahn, A.J., Suda, T., and Yoshiki, S. 1991. Recombinant human bone morphogenetic protein-2 stimulates osteoblastic maturation and inhibits myogenic differentiation in vitro. J. Cell Biol. 113: 681-687.

Yoshida, Y., Tanaka, S., Umemori, H., Minowa, O., Usui, M., Ikematsu, N., Hosoda, E., Imamura, T., Kuno, J., Yamashita, T., et al. 2000. Negative regulation of BMP/Smad signaling by Tob in osteoblasts. Cell 103: 1085-1097.

Zhang, Y.W., Yasui, N., Ito, K., Huang, G., Fujii, M., Hanai, J., Nogami, H., Ochi, T., Miyazono, K., and Ito, Y. 2000. A RUNX2/PEBP2 $\alpha$ A/CBFA1 mutation displaying impaired transactivation and Smad interaction in cleidocranial dysplasia. Proc. Natl. Acad. Sci. 97: 10549-10554. 


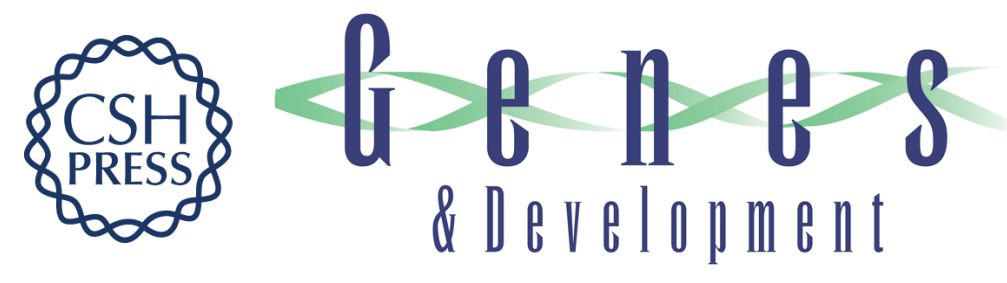

\section{Stat1 functions as a cytoplasmic attenuator of Runx2 in the transcriptional program of osteoblast differentiation}

Sunhwa Kim, Takako Koga, Miho Isobe, et al.

Genes Dev. 2003, 17:

Access the most recent version at doi:10.1101/gad.1119303

\section{Supplemental http://genesdev.cshlp.org/content/suppl/2003/07/23/17.16.1979.DC1 Material}

Related Content

References

License

Email Alerting

Service
STAT1 Sequesters Runx2 to Limit Bone Deposition

Sci. STKE August , 2003 2003: tw328-TW328

This article cites 44 articles, 15 of which can be accessed free at:

http://genesdev.cshlp.org/content/17/16/1979.full.html\#ref-list-1

Articles cited in:

http://genesdev.cshlp.org/content/17/16/1979.full.html\#related-urls

Receive free email alerts when new articles cite this article - sign up in the box at the top right corner of the article or click here.

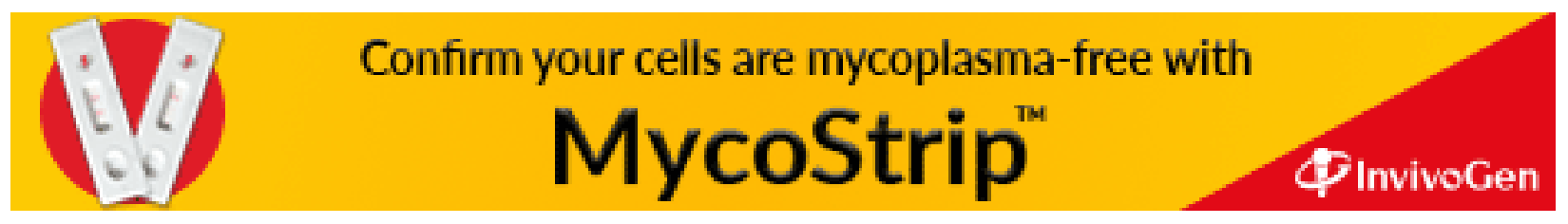

